
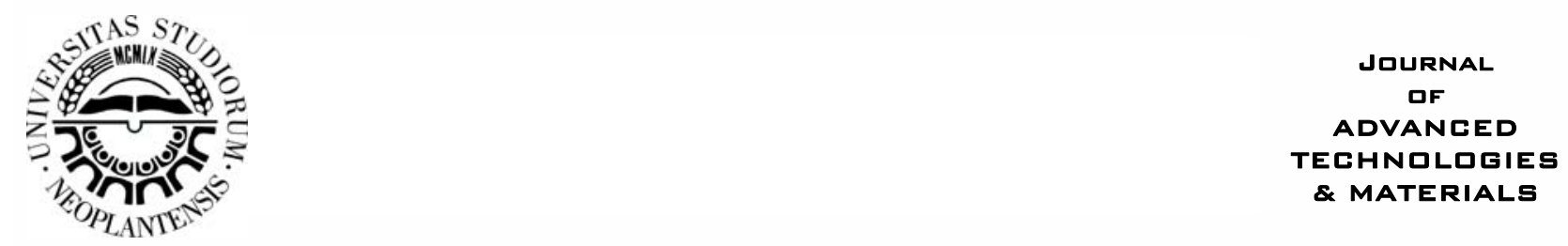

\title{
Finite Element Analysis of Extrusion Force and Work Characteristics of ECAP
}

\author{
Alex Llerena, Viktor Gonda * \\ Donát Bánki Faculty of Mechanical and Safety Engineering, Óbuda University, 1081 Népszínház u. 8, Budapest, Hungary
}

\begin{abstract}
A planar finite element model is created for modeling the equal channel angular pressing (ECAP) processing of copper, by which the technological parameters can be determined for different initial parameters of the ECAP process. The structure of the model is described, as well as the extraction of the force and work data, furthermore results for the effect of the initial parameters, e.g. the friction and the frictional model on the extrusion force and work characteristics are shown.
\end{abstract}

Key words: equal channel angular pressing, extrusion, friction model, finite element simulation.

\section{INIRODUCTION}

Equal channel angular pressing (ECAP) is a severe plastic deformation method by which large amount of strengthening can be achieved for metallic materials. The technological parameters of the processing, the extrusion force and the extrusion work, are affected by the extruded material type and state, extrusion temperature, the die geometry, such as the channel angle and the corner angle, extrusion rate, as well as the friction by the applied lubrication. The extrusion force varies through the processing, its characteristic can be evaluated as a function of the plunger stroke. The deformation work applied during the processing is calculated by the integration of the forcestroke function. A fraction of the work is stored in the material (stored energy) and released during recrystallization.

Equal channel angular pressing is a processing method in which a metal is subjected to an intense effort of plastic deformation through an extrusion channel without any corresponding change in the dimensions of the cross section of the sample. This procedure can be used to create ultrafine grain sizes in bulk polycrystalline materials. Principles of the ECAP process have been examined with reference to distortions in a sample to the sample goes through a die of ECAP, with special attention to the effect of different routes between consecutive passes [1,2].

Significant distortions in the structure of the grains were observed when a sample was pressed through a standard
ECAP die, therefore in a repeatedly pressed sample, it has been recognized that the general shear characteristics within the crystalline sample varies. This can be modified by the rotation of the sample between the individual passes [1]. Repeated pressing of the same sample is usually conducted in order to obtain very high imposed strains. At the same time, there is the opportunity to rotate the sample between consecutive passes to activate different shear planes and directions, thus improving the mechanical properties at room temperature by applying different routes. It is well known that plastic deformation induced by conventional forming methods can significantly increase the deformation resistance of metals. However, this increase is often accompanied by a loss of ductility. Recently found that the materials processed by ECAP after certain number of passes show along with a high strength and high ductility. This unusual behavior of materials, which is in contradiction with the classical loss of ductility with greater resistance trends was studied in [2].

In the present article, we analyze Equal channel angular pressing by the extrusion force and work characteristics. A planar finite element model is created for modeling the equal channel angular pressing (ECAP) processing of copper, by which the technological parameters can be determined for different initial parameters of the ECAP process.

In the following sections, first the ECAP background is described, then the structure of the finite element model is introduced, as well as the extraction of the force and work 
data, furthermore results for the effect of the initial parameters, e.g. the friction and the frictional model on the extrusion force and work characteristics are shown.

\section{CHARACTERISTICS AND TECHNOLOGY FORECAP}

In this section, the related works are described for ECAP experiments and the related improvements in the mechanical characteristics.

The ECAP method, based on the deformation of bulk materials by simple shear specimens, was developed in the 1970s. The absence of any change in the cross section of the sample created adequate conditions for the repeated deformations. At the beginning of the 1990s, the method was developed further and was applied for the first time to produce structures with submicron crystalline grain size. In ECAP, pressure blank is pressed several times in a special device through two channels with the same cross-section, which usually will intersect at the angle of $90^{\circ}$. If necessary, deformation can be performed at elevated temperatures [3]. A schematic of the ECAP process is shown in Fig. 1. For a given corner angle $(\psi)$ the higher the channel angle, the more degree of deformation is obtained.

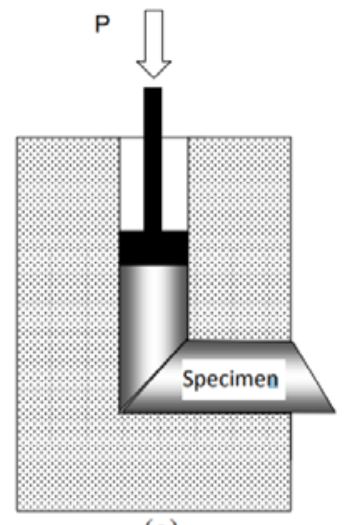

(a)

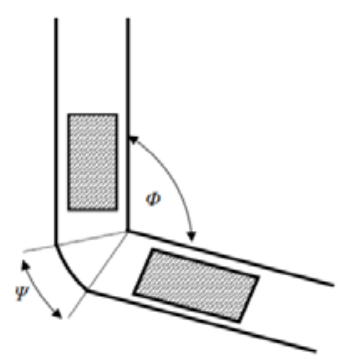

(b)
Fig. 1Equal-channel angular pressing: (a) schematic; (b) geometrical parameters [5].

\subsection{Characteristics of nano-crystalline alloys}

The mechanical attributes of the samples processed by ECAP were extensively studied by tensile and compressive tests [5]. Samples for the tests of tension and compression were cut, and the material pressed along the longitudinal axis. The tensile tests were carried out at room temperature to $2 \mathrm{~mm} / \mathrm{min}$ speed crosshead to collect information on the dependence of yield stress, the final tensile stress, reducing area and elongation in different routes of process and the number of passes [5]. Results of tensile tests are indicated in Fig. 2 and 3. In Fig. 2, reducing the area and elongation compared to the number of passes are displayed for each route of ECAP. In Fig. 3, is the yield stress and the tensile stress depending on the number of passes for each route are shown [5]. Some samples processed by ECAP were also investigated using compression tests. During compression, the shape of the cross section of the samples tended to change from circular to oval. In order to investigate the influence of the routes of the anisotropy in development process, measured the ratio of diameters larger and smaller cross-section for each route of the process following the

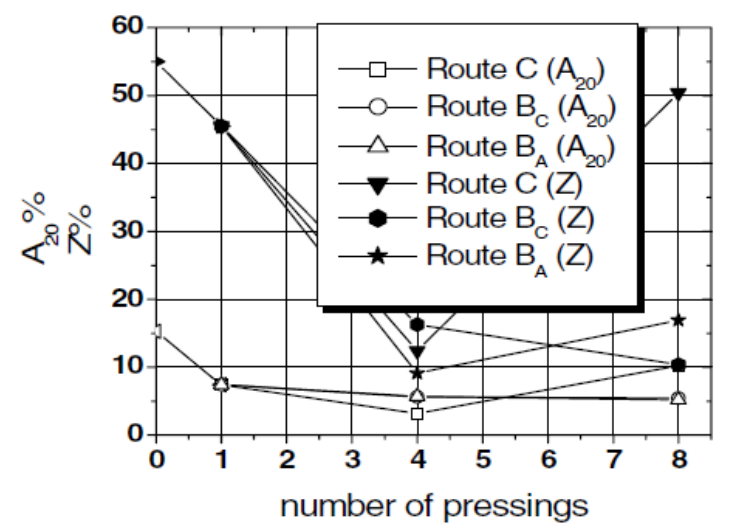

steps fourth and eighth of ECAP [3] (Fig. 4).

Fig. 2 Elongation (A20) and area reduction (Z) at ambient temperature vs. the number of ECAP passes for different routes [5]

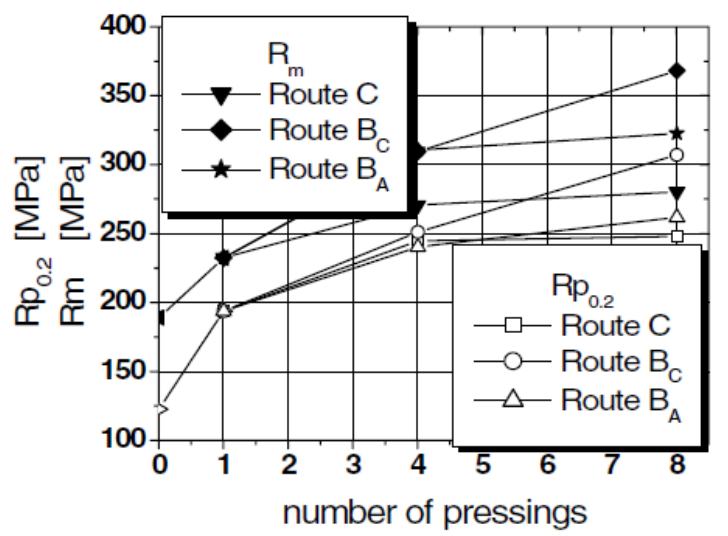

Fig. 3 Yield strength $\left(R_{p 0.2}\right)$ and ultimate strength $\left(R_{m}\right)$ at ambient temperature vs. the number of ECAP passes for different routes [5].

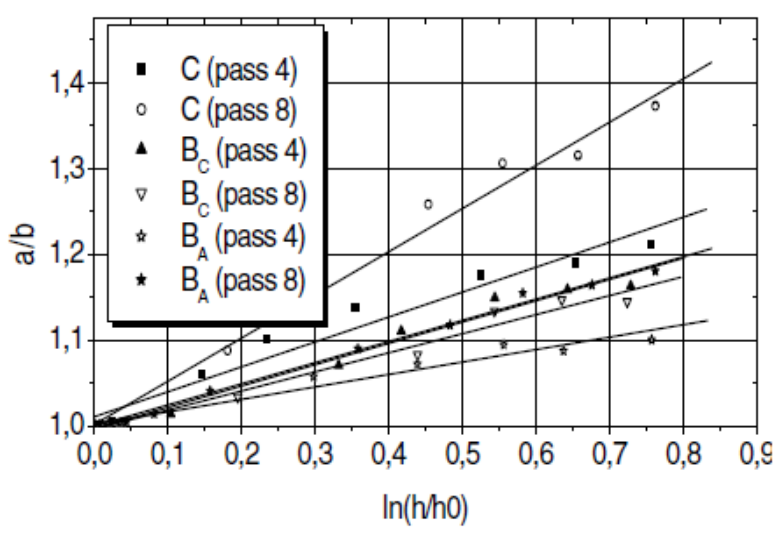

Fig. 4Diameter ratio vs. compressive strain at ambient temperature for Al 6082 after various ECAP passes [5]. 


\subsection{Producing bulk nanostructured metals and alloys by $S P D$ [4]}

The data for $\mathrm{Cu}$ processed by ECAP shown in Fig. 5 clearly demonstrate the enhanced strength as well as ductility with accumulated deformation on increasing the number of passes from 2 to 16 . At the time of the investigation in 2002, this was considered a very remarkable result, which had never been observed before in metals processed by plastic deformation [6]. Accordingly, the effect was termed the paradox of strength and ductility in SPD-processed metals', and the principles of this paradox are illustrated in Fig. 6.

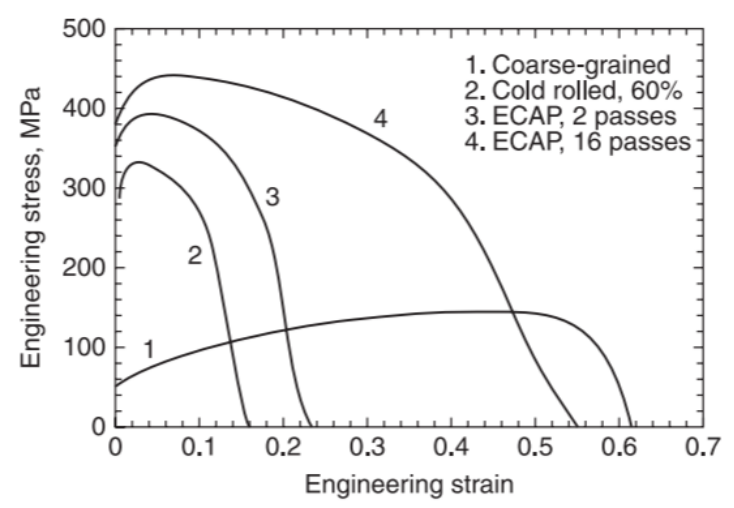

Fig. 5 Tensile engineering stress-strain curves for Cu tested at $22^{\circ} \mathrm{C}$ with a strain rate of $10^{-3} \mathrm{~s}^{-1}[6]$.

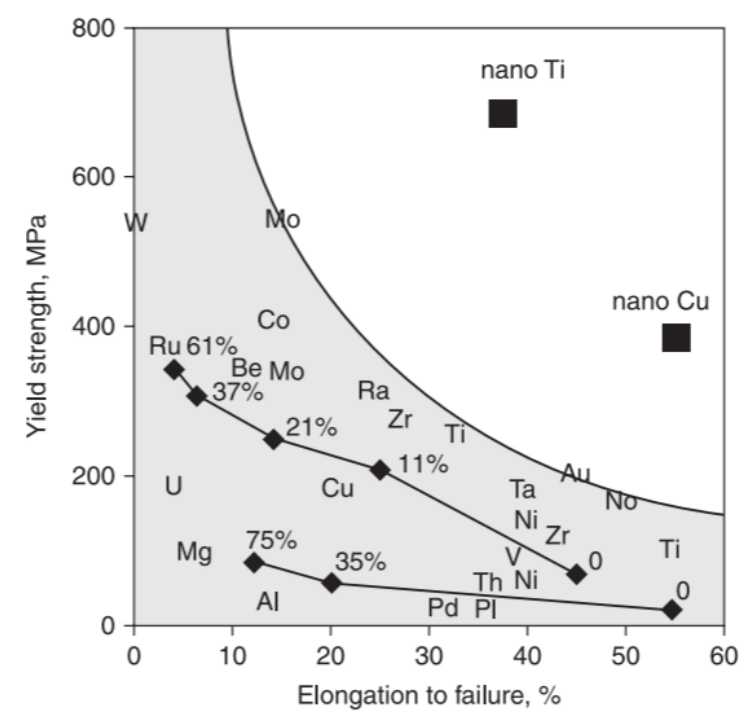

Fig. 6 The paradox of strength and ductility in metals subjected to SPD: the extraordinary combination of high strength and high ductility in nanostructured $\mathrm{Cu}$ and Ti processed by SPD clearly sets them apart from conventional coarse-grained metals [6]

\subsection{Response of copper to equal channel angular pressing with different processing temperature [5]}

Commercial purity copper was used as the experimental material in [7]. ECAP method was used to produce UFG structured copper. Before performing the ECAP process, the specimens were annealed at $600^{\circ} \mathrm{C}$ for $1 \mathrm{hr}$ to homogenize the microstructure. The ECAP processing was performed at room temperature and at elevated temperature of $220^{\circ} \mathrm{C}$ using a hydraulic press with a capacity of 60 tons. The ECAP die used in this process had an inner channel angle of $\varphi=90^{\circ}$ and outer channel angle of $\psi=20^{\circ}$; effecting high triaxial equal strain of 1.0 per pass [6].

After completion of the ECAP process, tensile specimens were prepared to a cross section of $3 \mathrm{~mm} \times 5 \mathrm{~mm}$ and a gauge length of $14 \mathrm{~mm}$ [7].

The ECAP processed copper specimens were evaluated for their physical/strength properties. Typical stress-strain characteristics of commercial purity copper exposed to equal channel angular pressing through route $\mathrm{C}$ (feeding) at room temperature is shown in Figure 7.

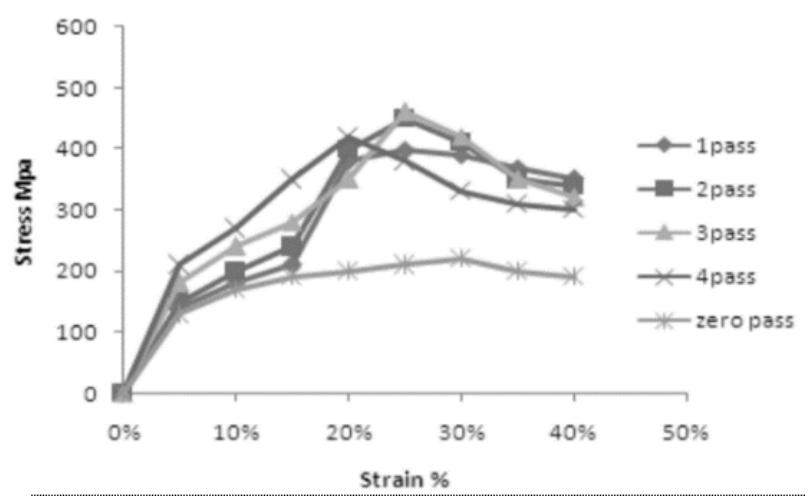

Fig. 7 Stress-strain graph for room temperature ECAP processed Cu [7].

It is seen that unstressed copper specimen exhibits a stressstrain proportional up to $10 \%$, followed by a load hold, elongation up to $30 \%$ results in to strain hardening, followed by a dip, indicating material failure.

After third pass, hardness, tensile strength and yield strength are not significantly improved compared with first and second passes. Because material attains the steady state (saturation of strength) and followed by dynamic recovery [8].

Typical stress-strain characteristics of commercial copper subjected to equal channel angular pressing at $220^{\circ} \mathrm{C}$ is illustrated in Fig. 8. It is seen that unlike the case of room temperature pressing, the stress-strain characteristics exhibits a distinct yield drop indicates strengthening of copper associated with ductility.

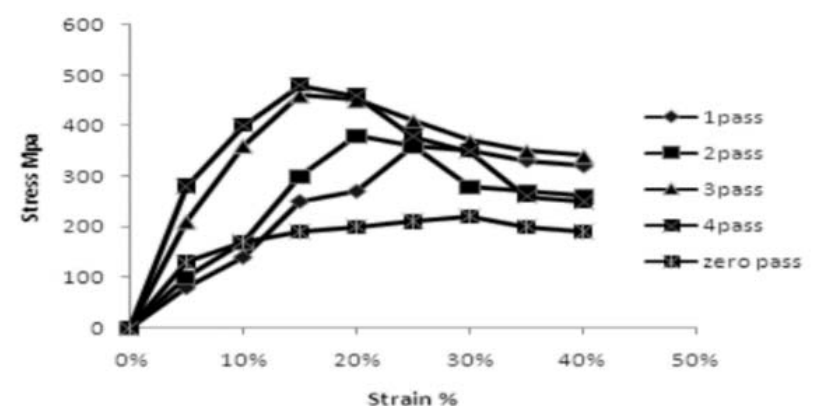

Fig. 8 Stress-strain graph for $220^{\circ} \mathrm{C}$ temperature ECAP processed $\mathrm{Cu}[7]$. 


\section{SimULATIONPROCEDURES}

Finite element simulations were carried out in MSC Marc. The general overview of the simulation method is depicted in Fig. 9. The planar geometry, the material properties for copper and the contact definitions are the input parameters. In the process, the friction model and friction parameters are varied. As an output, the extrusion force and extrusion work characteristics of the process are evaluated.

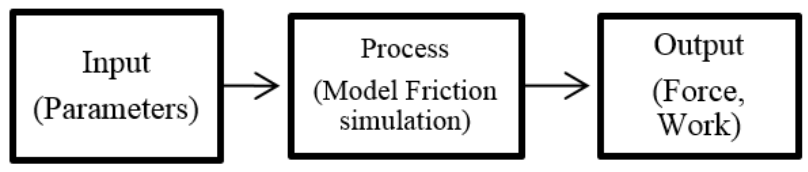

Fig. 9 General overview of the simulation method

In this work, the two friction models used are the Coulomb and Shear friction models. In Fig. 10 interrelation of the general parameters of the simulation are shown. The planar geometry used in the simulations is shown in Fig. 11. The channel and the plunger is modelled as rigid and the workpiece is a deformable body with work hardening characteristics. The geometry parameters of the channel are shown in Table 1. For the two frictional models, three equivalent friction cases were defined. The corresponding Coulomb $(\mu)$ and Shear $(m)$ model friction parameters are shown in Table 2.

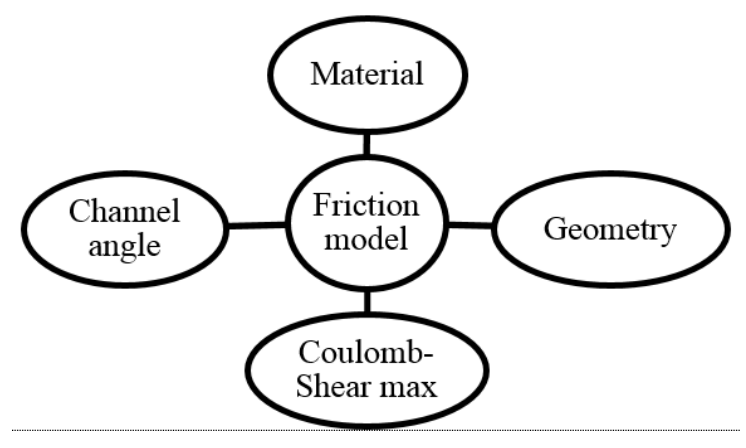

Fig. 10 General parameters used in the simulation

Table 1 - Parameters for the ECAP model simulation

\begin{tabular}{ll}
\hline Parameter & Dimension \\
\hline Diameter: & $10 \mathrm{~mm}$ \\
Cross section area: & $78.5 \mathrm{~mm}^{2}$ \\
Channel length: & $110 \mathrm{~mm}$ \\
Workpiece length: & $60 \mathrm{~mm}$ \\
Extrusion velocity: & $1 \mathrm{~mm} / \mathrm{s}$ \\
Channel angle: & $110^{\circ}$ \\
\hline
\end{tabular}

A snapshot of the extrusion process is shown in Fig. 12. The color map is for the von Mises stress in MPa.
Table 2 - Friction model parameters

\begin{tabular}{ccc}
\hline Case & Coulomb $(\boldsymbol{\mu})$ & Shear $(\boldsymbol{m})$ \\
\hline 1 & 0.10 & 0.17 \\
2 & 0.12 & 0.20 \\
3 & 0.14 & 0.24 \\
\hline
\end{tabular}

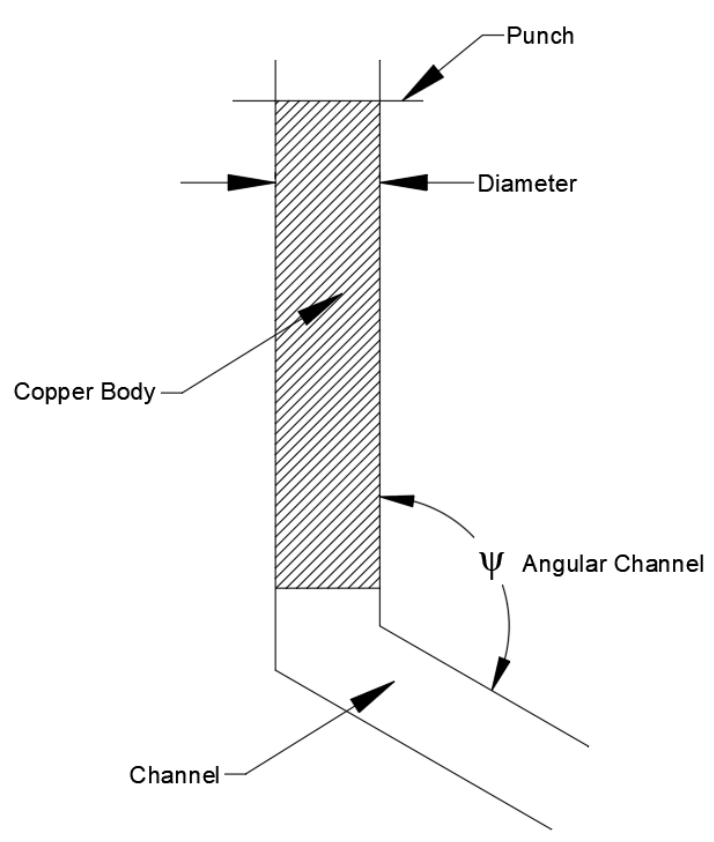

Fig. 11 Planar ECAP model in Marc
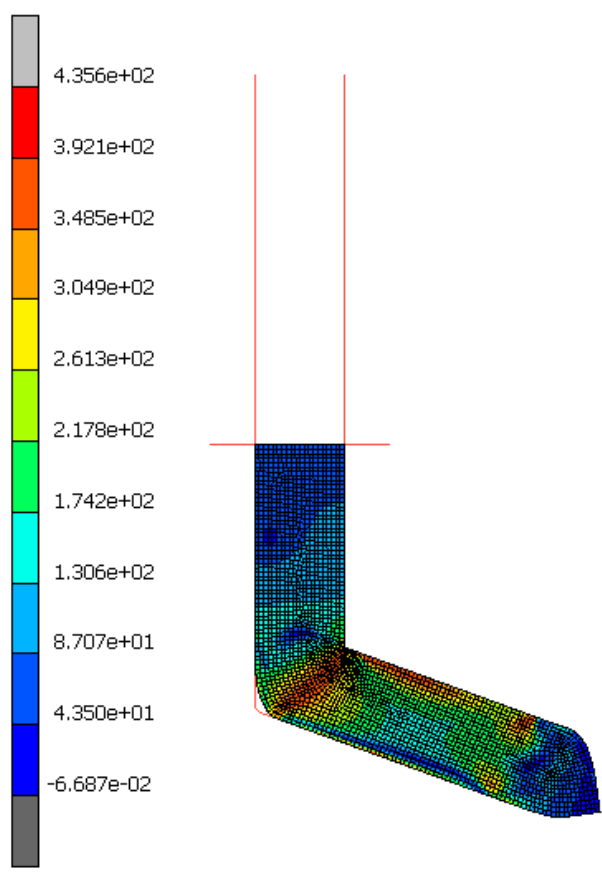

Fig. 12 Simulation results of the von Mises equivalent stress. The color map values are in $\mathrm{MPa}$. 


\section{RESULTS ANDDISCUSSION}

The results of the force-stroke characteristics for the Coulomb friction model are shown in Fig. 13. The higher the Coulomb friction coefficient the more force needed for the extrusion. The initial transients of the extrusion when the specimen bends into the channel is related to the first $10 \mathrm{~mm}$ of the stroke, and this results in a local maximum of the force. Subsequently, the steady extrusion process continues from a lower force level, but with increasing force needed due to the hardened material fills the output channel, therefore the friction force increases up to about a stroke of $30 \mathrm{~mm}$. In the last part of the stroke, the extrusion force decreases, as the contact length in the input channel decreases. At the steady state, the maximal forces are approximately $26 \mathrm{kN}, 29 \mathrm{kN}$ and $34 \mathrm{kN}$, for the Coulomb friction coefficient of $0.10,0.12$ and 0.14 , respectively.

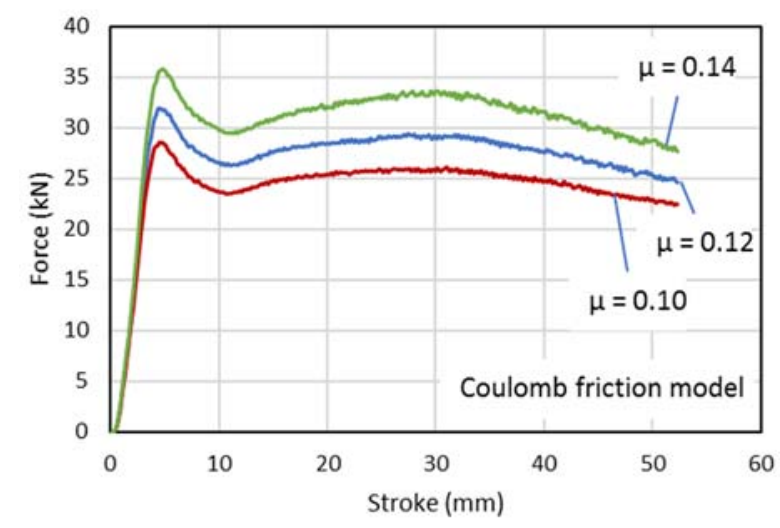

Fig. 13 Simulation results for the Force-Stroke characteristics of ECAP with the Coulomb model for different friction coefficients

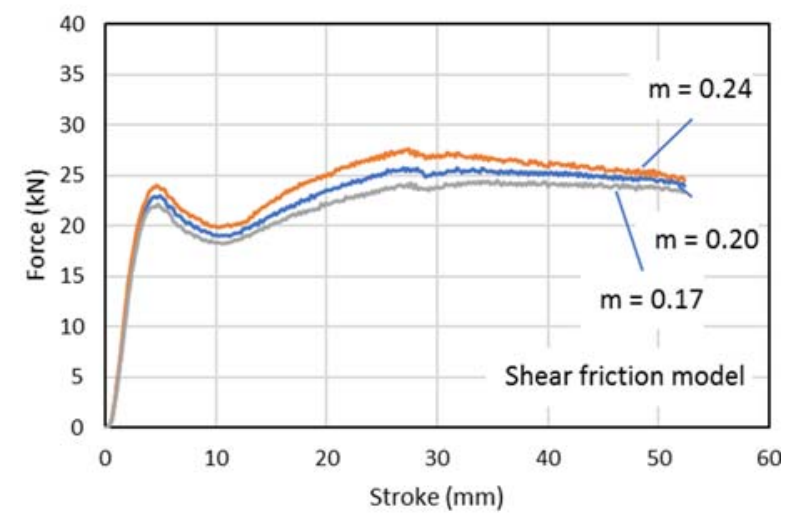

Fig. 14 Simulation results for the Force-Stroke characteristics of ECAP with the Shear friction model for different friction coefficients.

The results of the force-stroke characteristics for the shear friction model are shown in Fig. 14. It has a similar characteristic to the Coulomb friction model, but extrusion forces are lower in general. At the steady state, the maximal forces are approximately $23 \mathrm{kN}, 25 \mathrm{kN}$ and $27 \mathrm{kN}$, for the shear friction coefficient of $0.17,0.20$ and 0.24 , respectively.

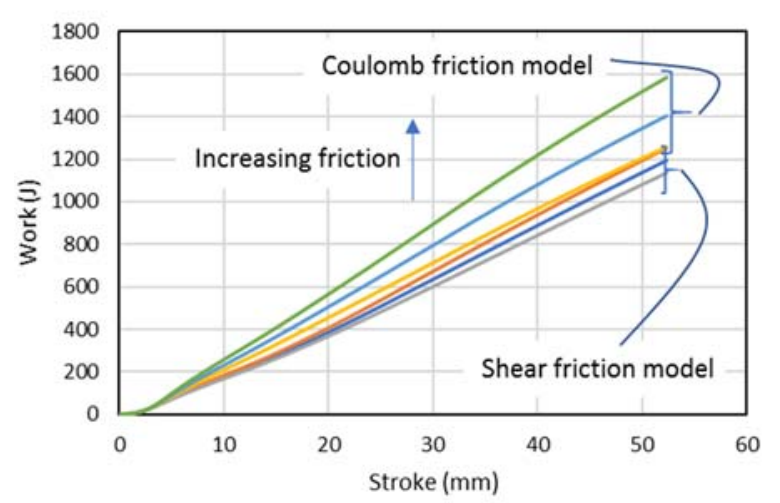

Fig. 15 Comparison of the Work-Stroke results for the Coulomb and Shear friction models.

The results of the work-stroke characteristics are shown in Fig. 15 for both the Coulomb and the Shear friction models. The total work for the extrusion for the different cases are shown in Table 3.

Table 3 - Extrusion work done in Coulomb and Shear model

\begin{tabular}{cccc}
\hline $\begin{array}{c}\text { Coulomb }(\boldsymbol{\mu}) \\
\text { coefficient }\end{array}$ & $\begin{array}{c}\text { Shear }(\boldsymbol{m}) \\
\text { coefficient }\end{array}$ & $\begin{array}{c}\text { Coulomb } \\
\text { Work }(\boldsymbol{J})\end{array}$ & $\begin{array}{c}\text { Shear } \\
\text { Work(J) }\end{array}$ \\
\hline 0.10 & 0.17 & 1256.2 & 1136.2 \\
0.12 & 0.20 & 1403.7 & 1194.3 \\
0.14 & 0.24 & 1585.2 & 1253.6 \\
\hline
\end{tabular}

\section{CONCLUSIONS}

A planar finite element model is created for modeling the equal channel angular pressing of copper, by which the technological parameters can be determined for different initial parameters of the ECAP process. Upon the results for the effect of the friction and the frictional model on the extrusion force and work characteristics, the following conclusions can be drawn:

- Related to the extrusion forces, by using the Coulomb friction model, higher forces are needed compared to the application of the Shear model, for the equivalent friction state. The force values are in the interval of $23 \mathrm{kN}$ to $34 \mathrm{kN}$, an acceptable range comparing to experimental values.

- Related to the work characteristics, the highest total work resulted in the Coulomb friction model. The total extrusion work ranges from about $1.1 \mathrm{~kJ}$ to about1.6 $\mathrm{kJ}$ for a single pass extrusion in the different friction models and friction coefficients.

\section{REFERENCES}

[1] Valiev R. Langdon Z. (2006) Principles of equalchannel angular pressing as a processing tool for grain refinement.. Progress in materials science, pp. 881-981. 
[2] Segal V. M. (1999) Equal channel angular extrusion: from macro-mechanics to structure formation. Materials Science and Engineering A 271, pp. 322333.

[3] Furukawa M., Horita Z., Nemoto M. (2001)Processing of metals by equal-channel angular pressing, Journal of materials science, pp. 2835-2843.

[4] Krállics G, Horváth M. Fodor Á. (2005) Influence of ECAP Routes on Mechanical Properties of a Nanocrystalline Aluminium Alloy. Periodica Polytechnica Ser. Mech. Eng. 48, pp. 145-150.

[5] Zhilyaev A., Pshenichnyuk A. (2011) Superplasticity and grain boundaries in ultrafinegrained materials, Elsevier.

[6] Valiev R., Estrin Y., Horita Z., Langdon T., Zechetbauer M. Zhu Y. (2006) Producing bulk ultrafine-grained materials by severe plastic deformation," in JOM, pp. 33-39.
[7] Vijayashakthivel A., Dath T. S. Krishnamurthy R. (2014) Response of copper to Equal Channel Angular Pressing with different processing temperature.," Procedia Engineering. 97, pp. 56-63.

[8] Lugo N., Llorca N., Cabrera J. Horita Z. (2008) Microstructures and mechanical properties of pure copper deformed severely by equal channel,pressing" Materials Science and Engineering, pp. 366-371.

[9] Fang, D., Zhang Z., Wu S., Huang C., Zhang H. Zhao N. (2006) Effect of equal channel angular pressing on tensile properties and fracture modes of casting $\mathrm{Al}-\mathrm{Cu}$ alloys," Materials Science and Engineering, pp. 305-313.

[10] El-Danaf E., Soliman M., Almajid A.A., El-Rayes M. (2007) Enhancement of mechanical properties and grain size refinement of commercial purity aluminum 1050 processed by ECAP," Materials science and engineering , pp. 226-234. 